\title{
Globe
}

Revue internationale d'études québécoises

Yannick Gasquy-Resch : Gaston Miron, le forcené magnifique.

Montréal, HMH, coll. " América ", 2003

\section{Martin Jalbert}

Volume 7, numéro 1, 2004

URI : https://id.erudit.org/iderudit/1000840ar

DOI : https://doi.org/10.7202/1000840ar

Aller au sommaire du numéro

Éditeur(s)

Globe, Revue internationale d'études québécoises

ISSN

1481-5869 (imprimé)

1923-8231 (numérique)

Découvrir la revue

Citer ce compte rendu

Jalbert, M. (2004). Compte rendu de [Yannick Gasquy-Resch : Gaston Miron, le forcené magnifique. Montréal, HMH, coll. « América », 2003]. Globe, 7(1),

217-220. https://doi.org/10.7202/1000840ar d'utilisation que vous pouvez consulter en ligne.

https://apropos.erudit.org/fr/usagers/politique-dutilisation/ 
L'étude de Pierre Serré est solide et conduite logiquement. Ses résultats, pris un à un, sont validés par de nombreuses autres études partielles ou qui ont traité par le biais les mêmes questions. Le grand apport de Serré est de montrer de façon systématique l'enchaînement logique à la source d'une réalité déjà connue et bien observée. Un groupe minoritaire unifié, ici les anglophones et les nouveaux citoyens qui s'associent aux anglophones, réussit à utiliser ses ressources électorales avec grand succès, ce qui semble a priori fort souhaitable si ce n'était du fait que l'électeur médian n'est pas très bien servi par cette dynamique. L'étude de Serré a aussi le mérite de lier la sociologie électorale et l'étude des institutions en ces années où l'on s'interroge sur la réforme des institutions électorales au Québec. La publication de cet ouvrage ne pouvait pas survenir à un meilleur moment.

Jean Crête

Université Laval

\section{Yannick Gasquy-Resch}

Gaston Miron, le forcené magnifique.

Montréal, HMH, coll. "América ", 2003.

Les passions, surtout naissantes, se nourrissent de toute ligne concernant leur objet. C'est notamment ce qui confère aux introductions de nature biographique une importance non négligeable. Quelques exemplaires de la collection "Écrivains de toujours " conservent, dans tels plis de ma bibliothèque, le souvenir de lectures voraces passées à entretenir des enthousiasmes verts, issus quelquefois de détails insignifiants mais d'une portée personnelle insoupçonnée. Ces livres apparaissent ainsi comme de précieux relais de contagion.

C'est à la catégorie des ouvrages introductifs qu'appartient Gaston Miron, le forcené magnifique, un "essai biographique " destiné à un public non spécialiste, mais qui aime la poésie . Quoique publié au Québec, le livre participe manifestement du désir de diffuser une œuvre "hors des frontières qui l'ont vule] naître " (p. 17) et paraît, en ce sens, se destiner essentiellement au lecteur non québécois - en témoigne le "petit glossaire mironien * et ses entrées telles que "maganer ", "giguer ", 


\section{REVUE INTERNATIONALE D'ÉTUDES QUÉBÉCOISES}

"Outaouais ", "poudrerie ", "Saguenay ". C'est de toute évidence à cette tâche pédagogique, indispensable, que se voue Yannick Gasquy-Resch, responsable par ailleurs du manuel Littérature du Québec, paru en France en 1994.

L'ouvrage se divise en deux parties correspondant au doublet l'homme et son œuvre. S'appuyant sur les textes de Miron - poèmes, textes en proses, lettres à Claude Haeffely, notes marginales de l'édition de 1994 de L'bomme rapaillé - et sur l'entretien radiophonique accordé à Jean Larose en 1990, la biographie s'intéresse principalement au rapport du poète à l'espace. Il se dégage de cette première partie une géographie mironienne dans laquelle les Laurentides, espace naturel et originel du lien affectif avec le territoire, s'opposent à Montréal, lieu urbain de l'altérité et du rétrécissement d'abord, puis de l'engagement politique. Quant à l'expérience parisienne de Miron, elle apparaît comme le moment où, à la faveur de la prise de conscience du caractère collectif des problèmes linguistiques, le désir de militance acquiert un degré d'urgence supplémentaire. Ces liens aux différents territoires, Yannick Gasquy-Resch les retrouve dans la poésie et l'imaginaire de Miron, au fil des suites et des séquences de L'bomme rapaillé, et plus précisément dans ce qu'elle appelle une " poétique de l'espace "(p. 31). Dans le dernier chapitre de l'ouvrage, le plus important, cette question de l'espace s'articule à la figure de la marche, celle d'un homme " porté par une énergie forcenée " (p. 130) - je ne sais pas encore comment il convient d'entendre ce mot de "forcené ", présent dans le titre de l'ouvrage et emprunté à Miron lui-même (" moi le noir / moi le forcené / magnifique "), sans que, flanqué ou pas de l'adjectif "magnifique ", il ne donne au poète une bien étrange allure de fou furieux... Ce dernier chapitre, dans lequel les poèmes sont directement envisagés, semble, en proportion, un peu trop bref, bien qu'il soit l'occasion de développer quelques recoupements fort pertinents avec le poète André Frénaud.

La principale réserve que je formulerais à l'endroit du livre de Gasquy-Resch concerne la trop grande importance accordée aux espaces référentiels - sans doute cette réserve procède-t-elle de ce que je me rallie volontiers à ceux qui consisidèrent que notre lecture de Miron tire profit d'un certain relâchement des liens, parfois tenus trop serrés, entre l'œuvre et son contexte historique, territorial et biographique; et que, éventuellement, ce relâchement sert mieux la poésie en général, et plus particulièrement celle que l'on tient pour "engagée. Vingt-cinq ans 
après “ Dépayser Miron - de Pierre Nepveu, texte-clé des études sur l'œuvre mironienne, le présent ouvrage apparaît comme un effort de reterritorialisation de cette poésie dans un sol, en définitive, peu problématique. Par ailleurs, on sent, dans l'analyse du rapport aux lieux, la persistance d'une certaine fascination pour des êtres qui feraient immédiatement corps avec leur monde et avec les grands espaces qui les entourent - "Miron, ne l'oublions pas, est un homme de la terre, un paysan " (p. 97) ; "La terre, tout autour, est son domaine " (p. 22). On peut regretter cette représentation du poète en une sorte de bûcheron, d'autant qu'elle recoupe indirectement l'opposition entre l'homme de la culture et l'homme de la nature. "Miron [arrivant à Paris] se dit Américain non pas seulement pour son rapport à l'espace mais pour sa façon d'embrasser la vie au quotidien loin des conventions, des hiérarchies, des formalismes qui entravent l'être dans son besoin d'action * (p. 74, je souligne). S'il est vrai que, dans la première lettre parisienne qu'il adresse à Haeffely et à laquelle Yannick Gasquy-Resch fait alors référence, Miron pose un diagnostic sévère sur la société française, il n'est cependant pas certain qu'il dise embrasser la vie au quotidien. J'hésiterais à généraliser les premiers mots de cette lettre - " me voici à Paris, moi le Canayen, le pas sortable, l'enraciné, le forestier, l'humusien, le continenteux, l'Américain etc. "-, plus près, il me semble, des dénigrements mi-revendicatifs mi-ironiques du "damned canuck " (qu'on se souvienne de "Mon nom est "Pea Soup". Mon nom est "Pepsi". Mon nom est "Frog" etc. ") ; j'hésiterais en effet à tirer d'un tel extrait l'essentiel du portrait d'un poète embrassant la vie au quotidien d'autant que son œuvre n'a cessé de dire la difficulté qu'il y a à avoir prise sur le réel quand on est $\alpha$ fait des trous noirs de l'univers .

Cette idée d'un enracinement immédiat paraît recouper, ici et là, d'autres antagonismes, entre oralité et écriture, pays de l'une et pays de l'autre : “ il [Miron] n'est pas de ce pays des grandes cultures que le temps a laissé mûrir, mais de ces espaces conquis à même le corps, où l'oralité l'a longtemps emporté sur l'écrit * (p. 74). Certes, les marques de parole vive, comme le démontre bien Yannick Gasquy-Resch, sont récurrentes dans les poèmes de Miron. Mais s'est-il vraiment "voué à l'oralité plus qu'à l'écriture * (p. 16) ? Ne spécifiait-il pas lui-même que cette oralité était "un mirage ", que sa poésie était "très écrite * (cité p. 138)? Par ailleurs, il me semble que sa culture personnelle était en grande partie issue de ces " grandes cultures que le temps a laissé mûrir ". Sa volonté de s'engager dans l'action, réaffirmée avec force dans une lettre de 
janvier 1960, n'empêche pas le poète, par exemple, de dévoiler à son correspondant les éléments d'une culture bien livresque, où philosophie, sciences sociales et poésie arrivent au premier rang. Enfin, la présupposition d'un rapport d'immédiateté de l'homme avec son territoire et sa patrie fait peut-être fi des déchirements profonds que suscite parfois la distance entre culture première et culture seconde, déchirements que Miron, comme Fernand Dumont, a évoqués avec beaucoup d'émoi. Il est vrai, et Yannick Gasquy-Resch le met en évidence, que plusieurs de ces oppositions, entre écriture et action par exemple, Miron les a lui-même énoncées. Mais en dernière analyse, ne ressort-il pas de l'univers mironien moins la figure d'un homme se rangeant d'un côté ou de l'autre de ces antagonismes que celle d'un homme écartelé dans la béance, déchiré entre des pôles conçus par lui, à certaines époques, comme effectivement contradictoires?

Personne n'est autorisé, spécialiste ou pas, à dire si Gaston Miron, le forcené magnifique est susceptible ou pas d'alimenter, voire de susciter des passions. Je n'en doute toutefois pas et le souhaite vivement.

Martin Jalbert Université Laval 